Published in final edited form as:

J Econ Asymmetries. 2011 December ; 8(2): 1-9. doi:10.1016/j.jeca.2011.02.002.

\title{
Major Findings from The Changing Body: Health, Nutrition, and Human Development in the Western World since 1700
}

\author{
Robert W. Fogel and \\ Center for Population Economics, University of Chicago, Booth School of Business and NBER \\ Nathaniel Grotte \\ Center for Population Economics, University of Chicago, Booth School of Business
}

\begin{abstract}
This paper discusses findings from The Changing Body: Health, Nutrition, and Human Development in the Western World since 1700 (Cambridge University Press) The book is built on the authors' work with 300 years of height and nutrition data and discusses their findings in the context of technophysio evolution, a uniquely modern form of rapid physiological development, the result of humanity's ability to control its environment and create technological innovations to adapt to it.
\end{abstract}

\section{Keywords}

Health economics; Nutrition; Height

\section{Introduction}

In April, Cambridge University Press published The Changing Body: Health, Nutrition, and Human Development in the Western World since 1700, a collaborative work by Professor Sir Roderick Floud (Gresham College), Professor Robert W. Fogel (University of Chicago Booth School of Business), Professor Bernard Harris (University of Southampton), and Professor Sok Chul Hong (Sogang University). The volume, first conceived more than two decades ago by Floud and Fogel, incorporates the authors' recent research on human development, height, and nutrition in continental Europe, England and Wales, and the United States. This paper reviews some of the major findings of the book, which aims to show

...that the health and nutrition of one generation contributes, through mothers and through infant and childhood experience, to the strength, health and longevity of the next generation; at the same time, increased health and longevity enable the members of that next generation to work harder and longer to create the resources which can then, in their turn, be used to assist the next, and succeeding, generations to prosper.

The mechanism that underlies this proposition is technophysio evolution, a term coined by Fogel and Dora Costa in a series of papers published in the late 1990s and expanded further in Fogel's 2004 book The Escape From Hunger and Premature Death, 1700-2100 
(Cambridge University Press). The theory of technophysio evolution states that the interplay between humanity's ability to control its environment and to create technological innovations has created a unique form of physiological development, which is much more rapid than traditional conceptions of Darwinian evolution. According to proponents of the theory, the proof lies in the dramatic changes that the human body has experienced in the past 300 years, which surpass the scale and size of changes brought about during many previous millennia.

The degree to which human bodies have changed in the course of the last 200 years can be illustrated by the following example. Circa 1850, the average American adult male stood about 5-foot-7-inches and weighed about 146 pounds. During the 1980s, the typical American male in his early thirties was about 5-foot-10 and weighed about 174 pounds. The amount of energy required for baseline maintenance (the energy required for rest and vital hygiene) for the American body of the 1980s is 2,378 calories per day.

If the French had been that large at the beginning of the nineteenth century, most of the available food (around 2,400 kcal per capita) would have gone to maintenance, with relatively little available to sustain work. Similar changes in stature occurred in other European countries (see Table 1). The Changing Body links changes in European and American body size to technological changes for diet and disease control. It is also important to note that other ways of regulating energy expenditure through intensity and duration of work also played a major role. Malnourished French peasants may have worked particularly long hours during harvest time with an intensity that could not have been maintained over the course of the year. Maternal malnutrition had substantial consequences for offspring, some of which were not apparent until older ages — or even future generations.

The balance of the chapters in The Changing Body is arranged geographically, collecting the stories of Britain, continental Europe, and the United States. Height data for continental Europe extend back to the second half of the seventeenth century, and confirm that men of the period were very short. The available data show declines in the heights of Swedish men (around 2.5 centimeters for the cohort born between 1740 and 1760), and men living in five separate provinces of the Habsburg Empire.

\section{Major Findings from the Data}

The eighteenth century was a difficult period in America. Settlers were burdened with rudimentary farming implements and limited agricultural knowledge. Harsh weather cut short the harvesting season. Opportunities to import and trade were limited, and the population was subjected to major fluctuations in food supply due to climate shocks. As a result, the supply of food was barely enough to sustain the agricultural laborers who were producing it. The diet was heavily composed of grains and cereals at first, and what little livestock was available was used more for milk and wool rather than meat. However, even in spite of these hardships, native-born American men were taller and had longer life expectancies than their European counterparts. The climate was well suited to agriculture, and the low population density resulted in less communication of disease. 
As for the nineteenth century, most scholars are in agreement that there was a general decline in the heights of British men and women between 1820 and 1850. Estimates put the extent of the decline (for men) at around 4.8 centimeters. Average heights began to rise once again after 1850, but even men who were born at the end of the nineteenth century were short by modern standards—about six centimeters shorter than British men in the 1980s.

In continental Europe, the average heights of French soldiers appear to have increased gradually over the nineteenth century, but heights decreased for Dutch soldiers during this period. Moreover, height and social status were positively correlated. In France, students at the elite École Polytechnique were 4 centimeters taller than the men conscripted into the national army between 1819 and 1826, and wealthy soldiers (those able to afford to hire a replacement) were taller than those who could not. Similar patterns have been observed in the Netherlands and Spain.

As heights declined, a concurrent mortality increase has been observed. The reason for this "arrest of progress" is not agreed upon, but it likely has some connection to the increasing urbanization in the nineteenth century. As this decline in stature reversed itself, mortality improvements were seen first in children between the ages of 4 and 9 after 1850 and later among to older-age individuals (see Figure 1). Improvements in sanitation contributed to the reduced mortality. This decline in mortality may have been associated with a decline in the virulence of tuberculosis, but the evidence is wanting. There is further debate as to whether the decline was greater in rural rather than urban areas.

As for diet, the evidence suggests that the British became net importers of food during the first half of the nineteenth century. The most dramatic change was in sugar, where imports increased by 150 percent between 1700 and 1850 . A number of researchers have suggested that population growth introduced the potential for a Malthusian crisis-an outpacing of the food supply by population - in the second half of the eighteenth century, but the data suggest that domestic food production stayed constant and the number of calories derived from imported foods had increased. Still, it is possible that a significant proportion of the British population had diets below levels necessary to maintain weight. Furthermore, there is evidence that households compensated for a dearth of calories by distributing a greater share of food to adult male workers, which may have contributed to the undernutrition of children and women, and to the elevation of their mortality rates.

At the beginning of the nineteenth century in the United States, new agricultural techniques were introduced and the frontier expanded westward, which resulted in a large increase in crop production. However, the U.S. population increased by 338 percent during the same period, cancelling out much of the gross benefit of this additional food, and crop production could not keep pace with the food required by the burgeoning industrial centers. As a result, per capita crop production stagnated or decreased, which raised prices and contributed to the nutritional decline of the population in the first half of the nineteenth century. The authors estimate that the average American adult male between the ages of 20 and 39 consumed about 2,900 calories daily in 1800 , which is roughly 20 percent higher than the average Englishman's intake at that time. A decline in the ability to produce wheat, rye, pork, and beef at levels that would maintain calories per capita in the face of population growth 
contributed to this deficit in available food: in 1850, daily caloric intake was 2,585 per adult male $20-39$, or 367 calories less than was available 50 years earlier. At the conclusion of the Civil War, per capita food production again increased, and by 1880, the American diet had reached a level that would persist to the 1970s and 1980s.

The end of the Civil War also marked the beginning of a decline in the total number of hours spent at agricultural labor in the United States, although, paradoxically, the work year of exslaves increased. Most African-Americans stayed in the south but a migration to the north began gradually to unfold. Agricultural technology advanced to such an extent that an hour's labor in 1900 could produce five times as much wheat as a century earlier.

Nineteenth-century Americans were plagued by low life expectancies. In 1850, life expectancy was around 40 years for whites and 23 years for blacks. These figures improved over the following twenty years but declined again in the 1880s, because of increased immigration and urbanization, which contributed to a severe disease environment that afflicted early Americans harshly. The primitive sanitary conditions in American cities disproportionately affected infants and children: in 1900, the infant mortality rate (IMR) in urban areas was about 180 per 1,000 births and about 117 per 1,000 births in rural areas (in 2009, the U.S. IMR was about 6 per 1,000 births). Within cities, mortality rates varied greatly, closely following differences in sanitary conditions in different wards. Farmers and those living in rural areas faced a harsh battery of diseases that included hookworm and malaria. Malaria, which was poorly understood into the early twentieth century, afflicted many, especially African Americas. The lone treatment, quinine, often failed to cure patients completely, and relapses were common, limiting the capacity for work.

Available data indicate that British heights improved over the course of the twentieth century despite a lack of significant progress during that century's first 20 years. Heights of children in continental Europe, which were below modern standards prior to World War I, improved as the century progressed. Germany, Greece, and Norway experienced these improvements between the World Wars; in other countries, improvements were not seen until 1945. Improvements in adult heights have been documented as well. The average heights of recruits in Bavaria, Belgium, Denmark, France, Italy, the Netherlands, Norway, Spain and Sweden increased between 3.1 and 11.1 centimeters during the first three-quarters of the twentieth century.

Mortality in Britain, which up until the beginning of the twentieth century was attributable primarily to infectious disease (between 25 and 30 percent of all deaths directly and more indirectly), fell sharply between 1901 and 1950. The greatest improvements in British mortality in the nineteenth century were between the ages of five and 44; the twentieth century saw improvements for infants and older adults. Elsewhere in Europe, life expectancies at older ages have increased significantly. In the middle of the twentieth century, a 65-year-old could expect to live for about another 14 years; by the end of the century, that figure had risen to 17.5. It appears that chronic disability is declining and healthy, high quality-of-life years are increasing. 
The examination of medical and pension records of Union Army veterans collected and digitized by the Center for Population Economics at the University of Chicago provides some insight into the relationship between height, morbidity, and mortality. The likelihood of being diagnosed with particular chronic diseases decreases as body-mass index (BMI) increases, up to a BMI of between 25 and 26. The risk continues to increase beyond the optimum BMI (see Figure 2). The risk of morbidity was generally lowest for the tallest individuals.

Figure 3 illustrates the correlation between BMI and labor force participation (a measure associated with economic productivity) in 1900. Individuals with low BMIs had, on average, labor force participation rates that were only a third of the average rate. The BMI associated with the highest labor force participation rates is the same as associated with low morbidity and mortality. The same pattern exists for white males in America today, as the hours spent at work by individuals in the labor force have become fewer and more efficient. American workers today work 30 percent fewer hours than workers in $1900 \mathrm{did}$, and time spent at leisure increased accordingly.

Acquisition of human capital flourished through the nineteenth and twentieth centuries despite health insults and other barriers, and the inequality between the rich and poor increased, and the effects (through pregnancy outcomes) could be observed for decades to come.

This complicated relationship underscores a difficulty in measuring economic growth while trying to capture imprecise but important elements of the human condition, and why quality of life cannot easily be measured in narrow economic terms.

\section{Implications for the Future}

What do these trends suggest for the future? People have been getting taller: At the end of the twentieth century, average heights of native-born Americans had increased by about 5 centimeters since 1910. Taller people are working more and earning more: a cross-cultural study from the end of the twentieth century found that an extra centimeter of height is associated with a gain in wage rates of about 5-10 percent (Schultz, 2005). People are retiring earlier: in 1900, 63 percent of males 65 and older were still on the job; by 2000, that figure had declined to around 17 percent. People are working less: those individuals who do work put in fewer hours (about 30 percent fewer than workers of 1900) but are more efficient. And people have gotten richer: real hourly wages increased 14 times over the twentieth century.

As a result, consumption patterns have changed. As technological advances have decreased the costs of food, clothing, and shelter, a larger proportion of income is today spent today on education and health care. Even as medical technology has improved and driven down the costs of treating certain diseases (especially those that can be prevented with inexpensive vaccines and antibiotics), the latest breakthroughs (such as advanced imaging techniques and organ transplants) demand high prices. Although life expectancies continue to increase and the average age of onset of chronic diseases is pushed later and later, the proportion of GDP that is spent on ever-improving health care will continue to increase because the 
income elasticity of the demand for health care is greater than one. It is no longer just undernutrition but also overnutrition that threatens to undercut medical progress and advances made in healthcare. The great availability of calories combined with modern sedentary lifestyles has meant an increase in the number of Americans classified as obese (sitting at or around a quarter of the population), putting them at greater risk for many diseases, including heart disease, stroke, hypertension, and some cancers. According to research on global BMI levels published recently in The Lancet, mean BMI has increased worldwide between 1980 and 2008 by .4 of a BMI unit for men and .5 of a BMI unit for women for women per decade (Finucane MM et al., 2011). The United States has the highest BMI of wealthy countries, but the British data mirror the trend. Although obesity emerged as a problem in an era of low mortality rates, in cross section, it is associated with increased risk of mortality and linked to diseases that include heart disease, stroke, hypertension, and some cancers.

\section{Conclusion}

In the conclusion, the authors acknowledge a certain tendency toward "the Whig interpretation of history: that history shows a constant improvement toward some ideal of human perfection." The authors furthermore acknowledge that the course of economic growth has consequences, including the public health consequences that will stem from the burgeoning obesity epidemic. A section titled "Possible Constraints" introduces a few wrenches that could grind the gears of the technophysio machine (such as the previously described Malthusian crisis, or a continuing AIDS epidemic), but an enduring faith in the "plasticity, flexibility, and responsiveness of the human body" makes it clear that the authors are optimistic that the trend of larger bodies and longer lives will continue into the future. The volume of historical data synthesized in this book may be its great strength.

The quality of available data and their nuances are major issues in this book. Dispersed throughout are several discussions of the difficulty in acquiring and handling these historical data, especially the issue of extrapolating information about the general population from the necessarily truncated historical records. For example, attempts to acquire heights of British children in the late eighteenth and early nineteenth centuries date back to the early 1980s (Floud and Wachter, 1982). Significant differences in the distributions of height were observed between the records of the poor boys of the Marine Society and the upper-class boys admitted to the elite Royal Military Academy at Sandhurst, highlighting significant physiological inequality. Military records provided a more representative picture of adult male heights of the period, which followed a generally upward trend, interrupted between 1825 and 1850 due to the "impact of urbanization." As The Changing Body is careful to note, these findings were scrutinized and debated by multiple scholars, for various reasons. In some cases, the samples overrepresented certain segments of society (e.g., military enrollees were more likely to be from the lower classes). Another similar issue is that many of these samples contain data on truncated samples, as military and similar organizations had minimum (and sometimes maximum) height requirements. Moreover, different techniques aimed at correcting for this bias are not universally agreed to be sufficient. Yet another issue is that health insurance records are tricky because the "sickness threshold" may have changed over time, and increased incidence of disease is more a "measure of 
increases in health awareness and in the provision of preventive services" than evidence of increased morbidity. In addition to the audience of economic historians, demographers, and epidemiologists, these discussions will be useful to anyone with an interest in hard-tomanage data.

It may prove difficult for any reader outside of the discipline to know what to make of the various conflicting academic opinions. Much of the book is quite technical, but those readers more interested in the narrative of changing bodies can easily bypass the equations. The scale of the inquiry and data analysis has led to a unique volume, one that the authors hope will prove to be a good story and a significant reference for years to come.

\section{References}

Finucane MM, et al. "National, Regional, and Global Trends in Body-Mass Index since 1980: Systematic Analysis of Health Examination Surveys and Epidemiological Studies with 960 Country-Years and 9.1 Million Participants, The Lancet. 2011; 377(9765):557-567.

Floud, R.; Fogel, RW.; Harris, BH.; Hong, SC. The Changing Body: Health, Nutrition, and Human Development in the Western World since 1700. Cambridge: Cambridge University Press; 2011.

Floud R, Wachter K. Poverty and Physical Stature: Evidence on the Standard of Living of London Boys 1770-1870, Social Science History. 1982; 6:422-452.

Schultz, TP. Productive Benefits of Health: Evidence from Low-Income Countries. In: LópezCasanovas, G.; Rivera, B.; Currais, L., editors. Health and Economic Growth. Cambridge: MIT Press; 2005. 


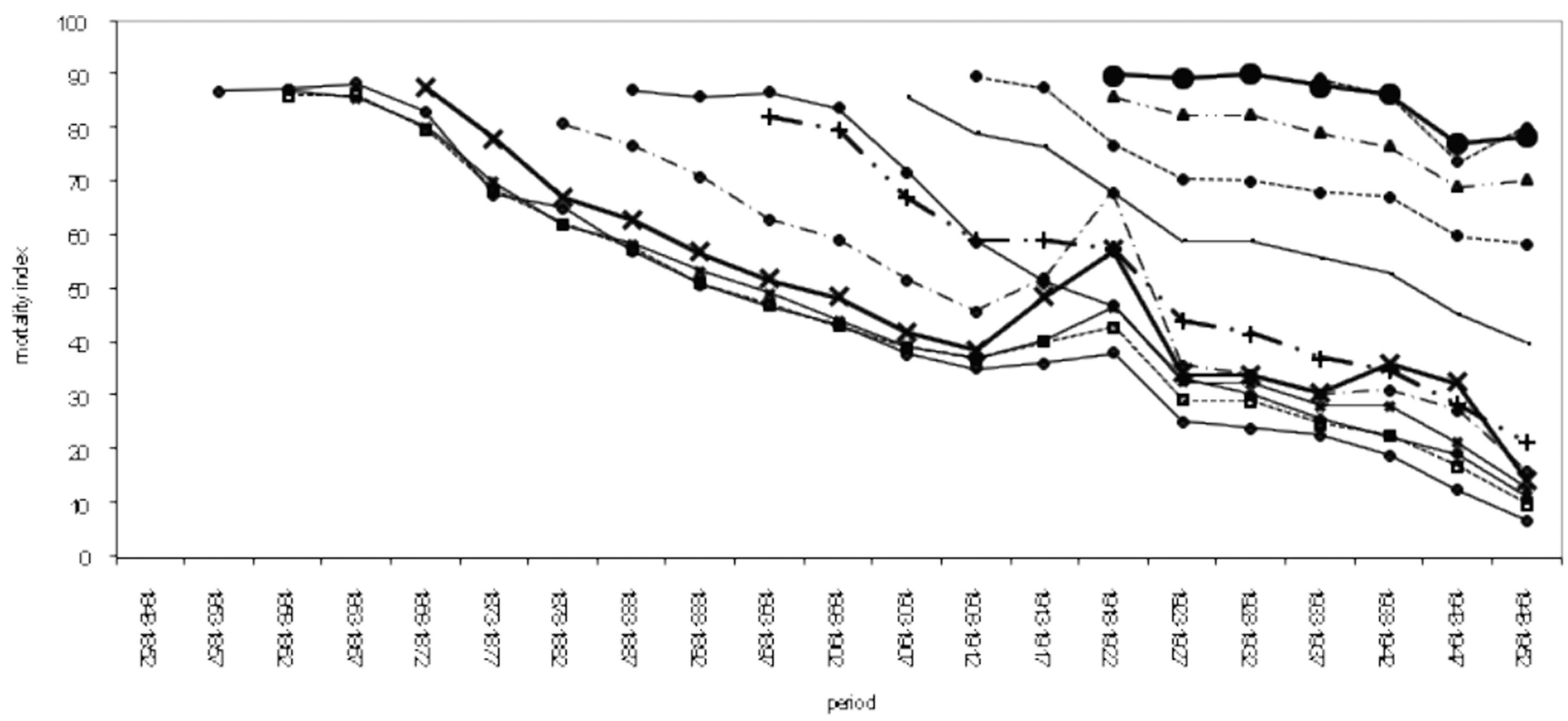

\begin{tabular}{|c|c|c|c|}
\hline 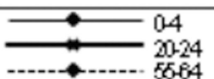 & 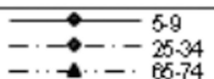 & 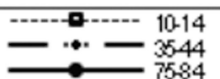 & 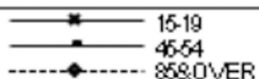 \\
\hline
\end{tabular}

Figure 1.

Age-specific mortality in England and Wales, 1840/52-1948/52

Source: Floud et al. 2011. (C) Cambridge University Press. Reprinted with permission. 

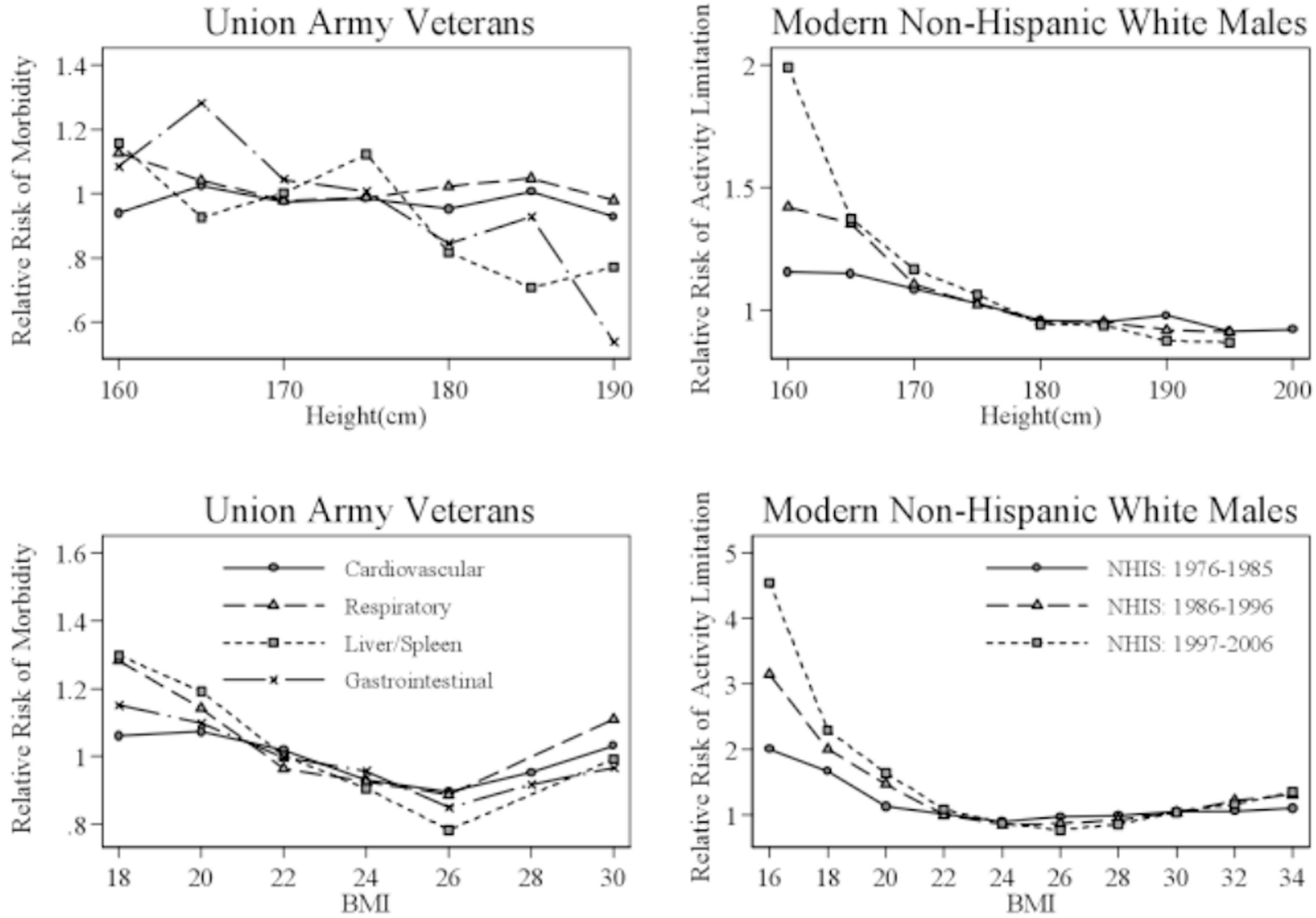

Figure 2.

Relative morbidity risk by BMI among Union Army veterans at ages 40 to 59 and relative risk of activity limitation by BMI among modern American non-Hispanic white males at ages 40 to 59

Source: Floud et al. 2011. (C) Cambridge University Press. Reprinted with permission. 
Non LFP and Poverty

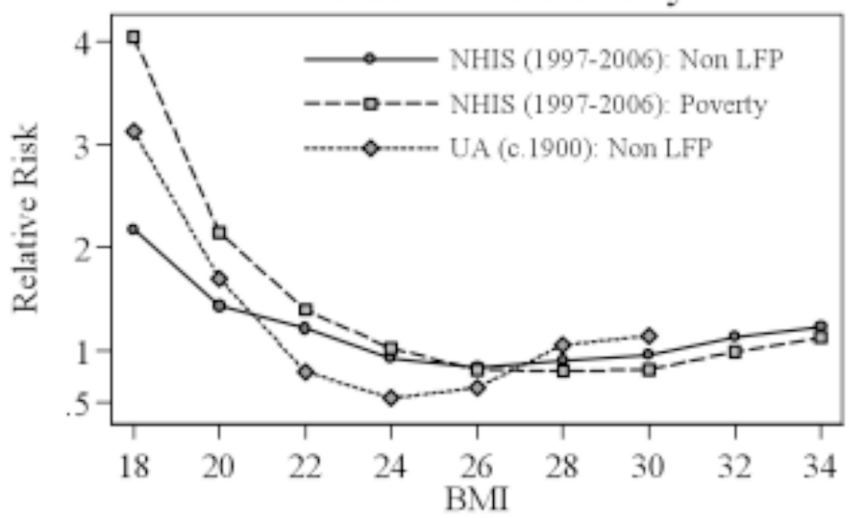

Earnings and Wealth

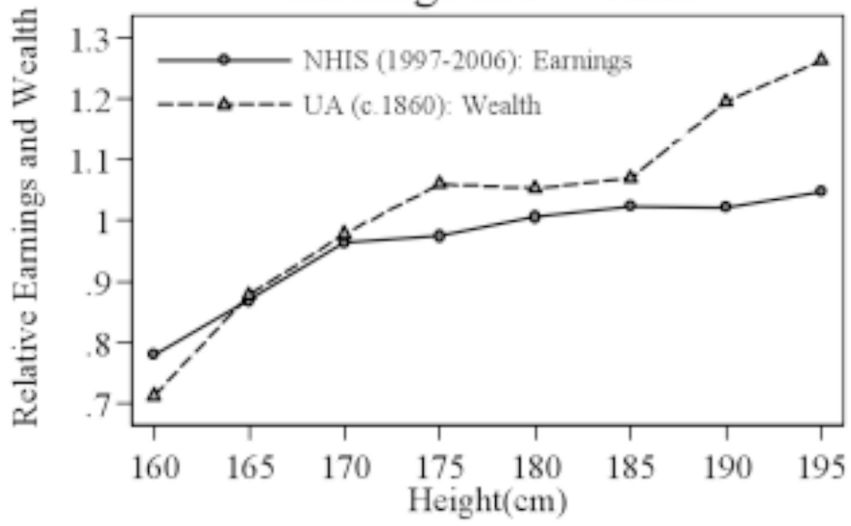

Figure 3.

Comparison of relative risk of low economic productivity (non labor force participation and poverty) by BMI and relative wealth and earnings by height, modern non-Hispanic white American males and Union Army veterans

Source: Floud et al. 2011. (C) Cambridge University Press. Reprinted with permission. 


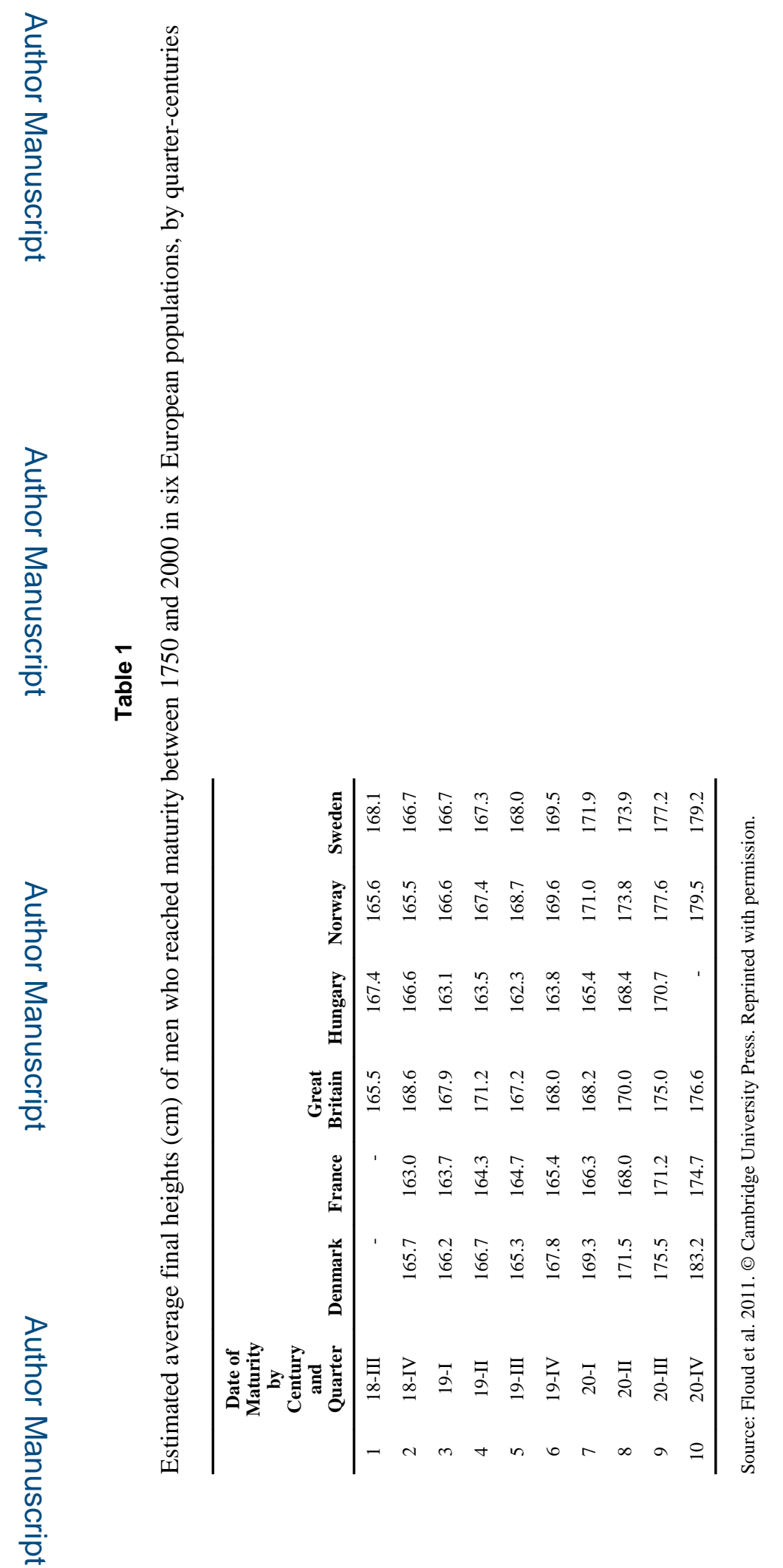

